\title{
ESTUDO DA PRODUÇÃO DE INULINASE POR YARROWIA LIPOLYTICA
}

\author{
U.S.SOUZA ${ }^{1}$, P.M.B. NUNES ${ }^{1}$, P.F.F. AMARAL ${ }^{1}$, M.H.M.ROCHA-LEÃO ${ }^{1}$ \\ ${ }^{1}$ Universidade Federal do Rio de Janeiro, Brasil. Departamento de Engenharia Bioquímica. \\ e-mail: ully_siqueira@ymail.com
}

\begin{abstract}
RESUMO - A enzima inulinase (2,1- $\beta$-D frutanohidrolase) pode ser aplicada na produção de xaropes com alto teor de frutose, pois realiza a hidrólise enzimática da inulina, produzindo frutose e frutooligossacarideos (FOS). Esta enzima pode ser obtida a partir de plantas, bactérias, fungos filamentosos e leveduras. A hidrólise da inulina apresenta grande importância na indústria de alimentos e também para a produção de etanol e acetona. $\mathrm{O}$ presente trabalho teve como objetivo principal estudar a utilização da inulina, polímero de reserva vegetal, como fonte de carbono por Yarrowia lipolytica e avaliar a produção de inulinase por esta levedura. Para tal, a levedura foi inoculada em meio NB (base nitrogenada $0,67 \%$, contendo inulina, glicerol ou glicose $0,5 \%$ $\mathrm{m} / \mathrm{v}$ ). As células foram cultivadas a $28^{\circ} \mathrm{C}, 250 \mathrm{rpm}$, por $24 \mathrm{~h}$. A biomassa celular e a concentração de substrato foram monitoradas ao longo do cultivo. Os resultados mostram que glicose e glicerol são fontes de carbono melhores para essa levedura. Em inulina houve crescimento lento, mas detectou-se atividade da inulinase. Portanto, esse estudo indica que $Y$. lipolytica tem potencial para produzir inulinase.
\end{abstract}

\section{INTRODUÇÃO}

A inulina é um polímero constituído de cadeias lineares de frutose com ligação do tipo $\beta$ 2,1-D-frutofuranose terminadas com resíduos de glicose (Trivedi et al., 2012). É muito utilizada na indústria de alimentos, pois sua composição confere sabor ligeiramente doce sem alterar o produto final e, por apresentar características peculiares, como a baixa solubilidade em água e capacidade de aumentar a viscosidade do meio, pode ser incorporada a barras de cereais e substituir a gordura em determinados produtos alimentícios (Pimentel et al., 2012).

Inulisanes (2,1- $\beta$-D-frutanos fructanohidrolases, CE 3.2.1.7) catalisam a hidrólise da inulina, produzindo inulo-oligossacarídeos, frutose e glicose como principais produtos (Neagu \& Bahrim, 2011). Entre as enzimas industriais, a inulinase tem recebido muita atenção por poder ser amplamente aplicada na produção de etanol e por ser muito eficiente no preparo de xarope de frutose a partir de inulina (Gao et al., 2007, Dilipkumar et al., 2011). Diferentes microrganismos são capazes de produzir inulinases, entre eles, as leveduras Kluyveromyces marxianus e Pichia guilliermondiie (Cazetta et al., 2005, Gong et al., 2007) e os fungos filamentosos Penicillium janczewskii e Aspergillus niveus (Pessoni et al., 2004; Souza-Motta et al., 2005).

O processo convencional de obtenção da frutose é realizado mediante uma transformação enzimática que culmina na isomerização da glicose a frutose a partir do amido e, devido à sua extensa utilização industrial (indústria alimentícia e farmacêutica), processos alternativos de produção estão sendo estudados e a produção deste açúcar a partir da hidrólise da inulina têm se mostrado promissora. A formação de frutose a partir de inulina envolve somente 1 etapa de 
hidrólise e pode proporcionar rendimentos superiores a 95\% (Souza-Motta et al., 2005, Nascimento, 2012).

Yarrowia lipolytica é um microrganismo estritamente aeróbio, eucariótico, dimórfico, do reino Fungi, pertencente à classe dos Ascomicetes, subclasse Hemiascomicetes. É um fungo de grande aplicação biotecnológica e tem sido utilizado como modelo de estudo do dimorfismo, tolerância ao sal, expressão de proteínas heterólogas, e acúmulo de lipídeos (Bankar et al., 2009).

Esta levedura não é considerada patogênica, provavelmente devido a sua incapacidade de sobreviver acima de $35^{\circ} \mathrm{C}$ (Pérez-Campos \& Dominguez, 2001) e, portanto, é utilizada em aplicações industriais como na produção de proteínas de microrganismos unicelulares, aroma de pêssego e ácido cítrico, em processos considerados pela American Food and Drug Administration como GRAS (Generally Regarded As Safe - Geralmente Reconhecido como Seguro) (Tsugawa et al., 1969). Além disso, excreta várias enzimas, como proteases, lipases, esterases e fosfatases, todas de grande interesse biotecnológico (Nicaud et al., 2002).

$Y$. lipolytica tem se mostrado muito versátil e numerosos trabalhos relatam a capacidade desta levedura em utilizar diferentes componentes de meio de cultura, entre eles óleo de oliva, óleo de soja, ácido oleico, glicerol, resíduos agroindustriais e, sabe-se que a produção de uma enzima por uma levedura é influenciada diretamente pelo tipo de substrato presente no meio de cultivo (Zinjarde \& Pant 2002; Amaral et al.2007, Nunes et al., 2014).

O presente trabalho se propôs a avaliar a capacidade de $Y$. lipolytica de utilizar a inulina como fonte de carbono para seu crescimento e detectar a produção da enzima inulinase durante o cultivo.

\section{MATERIAIS E MÉTODOS}

\subsection{Microrganismo}

A levedura utilizada no presente trabalho foi uma cepa selvagem de Yarrowia lipolytica IMUFRJ 50682 selecionada de um estuário da Baía de Guanabara no Rio de Janeiro, Brasil (Hagler \& Mendonça-Hagler, 1981) e identificada pelo Instituto de Microbiologia do Centro de Ciências da Saúde da Universidade Federal do Rio de Janeiro. As células são conservadas por repiques regulares em tubo de ensaio com meio YPD ("Yeast Extract, Peptone, Dextrose") contendo (em p/v): extrato de lêvedo $1 \%$, peptona $2 \%$, glicose $2 \%$ e solidificado com agar-agar $2 \%$. Após incubação a $28^{\circ} \mathrm{C}$ (Barth \& Gaillardin, 1997) por 48 horas na estufa, as culturas são refrigeradas a $4^{\circ} \mathrm{C}$.

\subsection{Obtenção do Inóculo e cultivo em diferentes fontes de carbono}

As células foram primeiramente cultivadas em erlenmeyer de $500 \mathrm{~mL}$ contendo $200 \mathrm{~mL}$ de meio YPD ( $2 \%$ glicose; $2 \%$ peptona; $1 \%$ estrato de lêvedo, $\mathrm{m} / \mathrm{v}$ ) em um incubador rotatório a $28^{\circ} \mathrm{C}$ e $160 \mathrm{rpm}$. Após 48 horas foram centrifugadas, lavadas e inoculadas no meio Nitrogen Base, NB $(0,67 \%$ base nitrogenada) contendo $0,5 \%$ de inulina, glicerol ou glicose. As células foram inoculadas em quantidade suficiente para obter-se uma concentração inicial de células de $1 \mathrm{~g} / \mathrm{L}$ e incubadas em incubador rotatório a $28^{\circ} \mathrm{C}$ e $250 \mathrm{rpm}$.

\subsection{Crescimento celular}

O crescimento celular de $Y$. lipolytica estudado em três diferentes fontes de carbono (glicose, glicerol e inulina) foi monitorado por medidas de densidade óptica a $570 \mathrm{~nm}$ e em espectrofotômetro 
UV-Vis Bel Photonics e esses valores convertidos para mg p.s. cé /mL usando-se um fator de conversão previamente determinado em curva de peso seco.

\subsection{Atividade enzimática}

As amostras retiradas de uma em uma hora foram centrifugadas e o sobrenadante foi utilizado para determinação da atividade enzimática de acordo com Pessoa Junior (1995). Para isso, 0,20 mL de solução que continha a enzima foi misturada em um tubo de ensaio com $0,8 \mathrm{~mL}$ de inulina $2 \%$, Tampão citrato-fosfato a $50^{\circ} \mathrm{C}$, durante 10 minutos, utilizando o reagente ácido 3,5-dinitrosílico (DNS), com método adaptado de Miller (1959) e Kameda (2007). A leitura foi realizada a $540 \mathrm{~nm}$.

Uma unidade de atividade da inulinase (U) é definida como a quantidade de enzima necessária para catalisar a hidrólise da inulina, com a formação de um micromol $(\mu \mathrm{mol})$ de frutose por minuto, nas condições do teste segundo Pessoa Junior (1995).

\section{RESULTADOS E DISCUSSÃO}

\subsection{Avaliação do Crescimento Celular em Diferentes Fontes de Carbono}

Para avaliar o comportamento da cepa Yarrowia lipolytica IMUFRJ 50682 em inulina, outras fontes de carbono foram também utilizadas de forma a comparar. O crescimento de $Y$. lipolytica IMUFRJ 50682 utilizando glicerol e glicose já foi avaliado em estudos anteriores (Pereira-Meirelles, 1997; Amaral, 2003). No entanto, o comportamento da levedura frente à inulina ainda é desconhecido. A Figura 1 apresenta os perfis de crescimento da levedura $Y$. lipolytica cultivada em meios de cultura com glicose, glicerol e inulina como fonte de carbono.

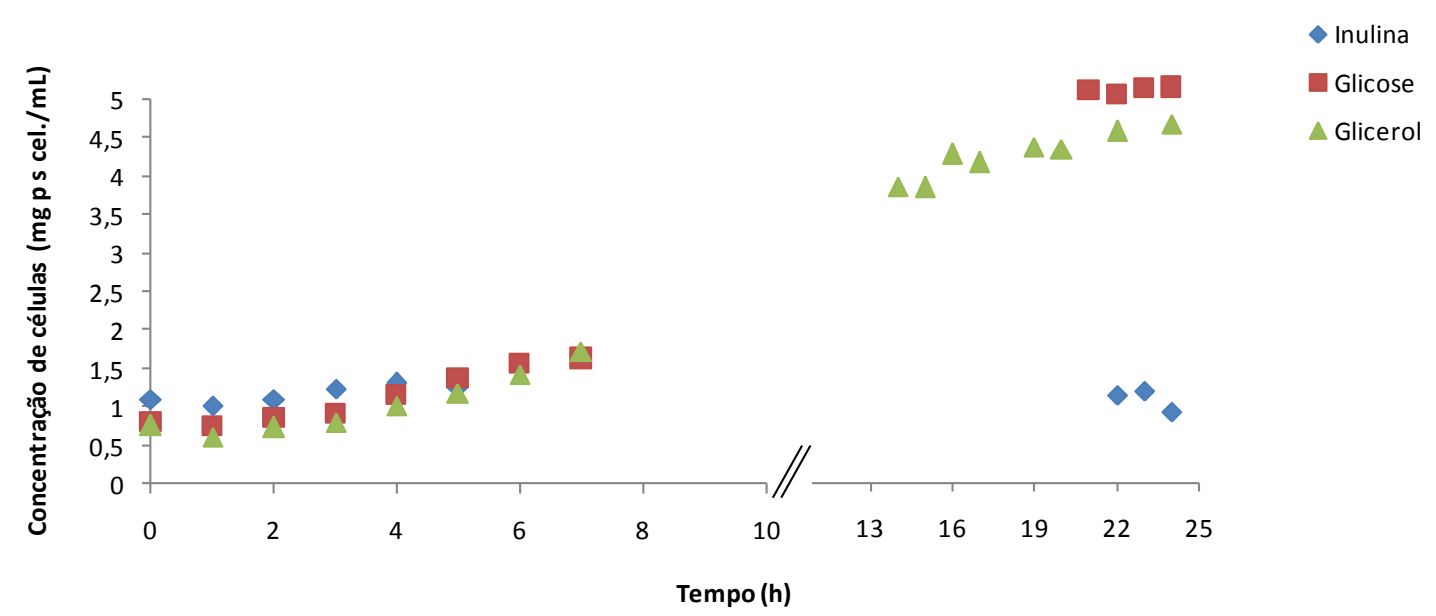

Figura 1 - Cinética de crescimento celular de Yarrowia lipolytica na presença de glicose, glicerol e inulina como fontes de carbono.

As cinéticas de crescimento celular apresentadas na Figura 1 mostram que os meios contendo glicose e glicerol favorecem o crescimento da levedura, com uma maior produção de biomassa em 24 $\mathrm{h}$ de cultivo (Tabela 1). Porém, na presença de inulina, o crescimento celular foi discreto e ao final de 24 h observou-se decréscimo da biomassa celular. Portanto, o meio de cultura contendo inulina não favoreceu o crescimento celular, nestas condições. 
Tabela 1 - Taxa específica de crescimento celular $(\mu)$ e variação de biomassa $(\Delta \mathrm{X})$ de $Y$. lipolytica, na presença de diferentes fontes de carbono.

\begin{tabular}{ccc}
\hline Substrato & $\Delta \mathrm{x}_{24 \mathrm{~h}}(\mathrm{mg} \mathrm{p} \mathrm{s}$ cél./ $\mathrm{mL})$ & $\mu\left(\mathrm{h}^{-1}\right)$ \\
\hline Glicerol & 3,69 & 0,18 \\
Glicose & 4,10 & 0,16 \\
Inulina & $-0,23$ & 0,08 \\
\hline
\end{tabular}

*Valores obtidos através da média de pelo menos três cinéticas de crescimento para cada formulação de meio de cultura

Observando-se as taxas específicas de crescimento celular $(\mu)$ também apresentadas na Tabela 1 , calculadas na a fase exponencial de crescimento celular para as cinéticas realizadas na presença das diferentes fontes de carbono testadas, é possível observar que os cultivos que apresentaram maior $\mu$ foram os que continham glicose e glicerol. E apesar da inulina ter sido menos eficiente na produção de células, houve crescimento celular entre 1 e $4 \mathrm{~h}$ de cultivo, o que indica que, provavelmente, $Y$. lipolytica utilizou esta fonte de carbono de alguma forma e que inulinases extracelulares tenham sido produzidas.

Gong e colaboradores (2007) estudaram as condições de produção de inulinase pela levedura marinha Pichia guilliermondii e observaram que as melhores condições para crescimento e produção da enzima foram observadas quando extrato de levedura e peptona foram utilizadas como fonte de nitrogênio. Portanto, o meio NB pode estar interferindo no crescimento da levedura utilizada no presente trabalho e outras fontes de nitrogênio devem ser avaliadas para otimizar seu crescimento.

Visto que alguns trabalhos relatam a possibilidade de a maior parte desta enzima estar associada à parede celular (Kirby \& Davies, 1970), é importante favorecer o crescimento celular para a detecção de possíveis inulinases presentes na célula de $Y$. lipolytica. Existem relatos na literatura de que esta levedura apresenta outras enzimas ligadas à parede celular. Pereira-Meirelles et al. (2000) relataram que Yarrowia lipolytica pode produzir três frações de lipases: a intracelular, a ligada à membrana celular e a extracelular, dependendo da disponibilidade do substrato no meio de cultivo.

\subsection{Detecção da Produção de Inulinase}

A produção de inulinase por $Y$. lipolytica ocorreu nas primeiras horas de cultivo, associada ao discreto crescimento celular. $\mathrm{O}$ máximo de atividade de inulinase detectado foi de $1,03 \mathrm{U} / \mathrm{L}$ às $3 \mathrm{~h}$ de cultivo.

Foram detectadas baixas atividades enzimáticas produzidas por esta levedura (Figura 2), mas, considerando que trabalhos anteriores relatam que esta levedura não produz invertase (Pereira-Meirelles et al., 1997) conferiu-se a atividade detectada à presença de inulinases. 
\Concetração celular

Inulinase

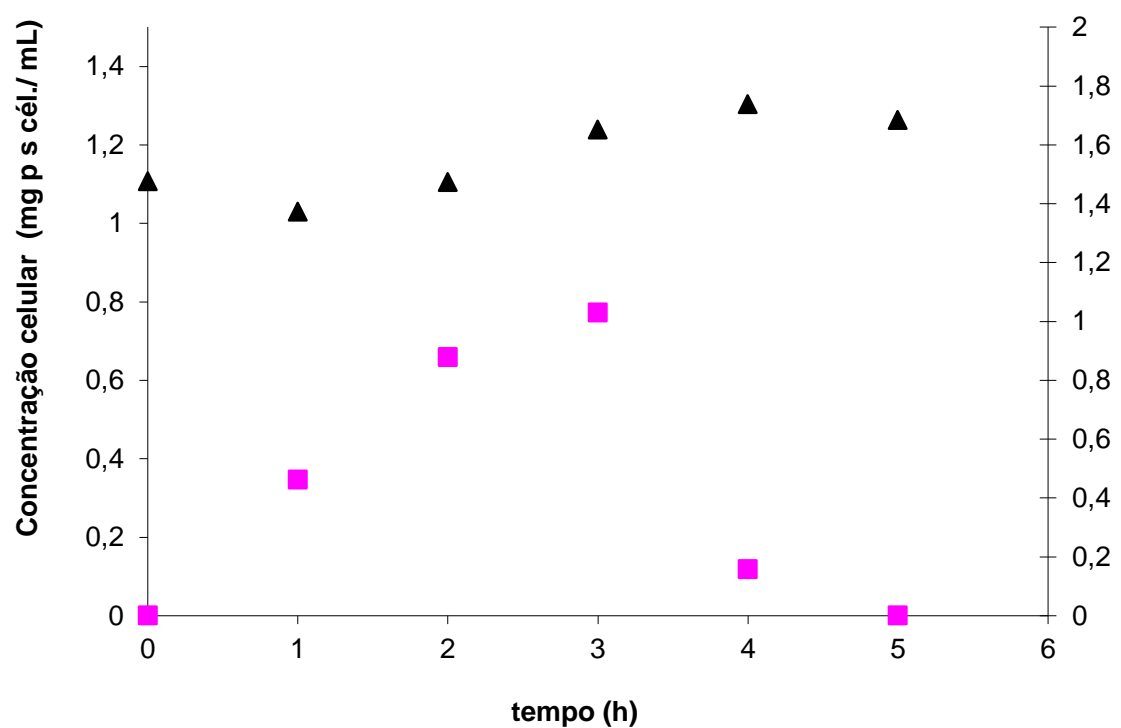

Figura 2 - Cinética de produção de inulinase por Yarrowia lipolytica na presença de inulina como fontes de carbono.

As leveduras do gênero Kluyveromyces são consideradas as mais promissoras na produção desta enzima e podem crescer rapidamente atingindo alta concentração celular em um curto período de tempo, produzindo grandes quantidades da enzima inulinase (Hensing et al., 1994). A composição do meio de cultivo afeta sensivelmente a excreção enzimática realizada por Kluyveromyces marxianus. Meios de fermentação contendo compostos nitrogenados, como extrato de levedura, aminoácidos e uréia, aumentam as taxas de produção da enzima. Portanto, estudos de otimização do meio de cultura podem levar a uma otimização da produção enzimática por Y. lipolytica.

\section{CONCLUSÃO}

Em face aos resultados apresentados, conclui-se que Yarrowia lipolytica foi capaz de produzir inulinases, ainda que em pequena quantidade. Estudos posteriores devem ser realizados adequando meio de cultura, $\mathrm{pH}$ e a forma de condução do processo para otimizar o crescimento da levedura em meio com inulina e, principalmente, a produção de inulinase pela mesma.

\section{REFERENCIAS}

AMARAL, P.F.F. (2003). Emprego de carreador de oxigênio na produção de lipase por Yarrowia lipolytica, Dissertação (Mestre em Ciências), Escola de Química - Universidade Federal do Rio de Janeiro, Rio de Janeiro, Brasil.

AMARAL, P.F.F., DE ALMEIDA, A.P. R., PEIXOTO, T., ROCHA-LEAO, M. H. M., COUTINHO, J.A., COELHO, M. A. Z. Beneficial effects of enhanced aeration using perfluorodecalin in Yarrowia lipolytica cultures for lipase production. World J. Microbiol. Biotechnol., v. 23(3), p. 339-344, 2007.

BANKAR, A. V., KUMAR, A. R., \& ZINJARDE, S. S. Environmental and industrial applications of Yarrowia. Appl. Microbial. Biotechnol., v. 84(5), p. 847-865, 2009. 
BARTH, G. \& GAILLARDIN, C. Physiology and genetics of the dimorphic fungus Yarrowia lipolytica. FEMS Microbiol. Rev., v.19, p.219-237, 1997.

CAZZETA, M.L. Estudo da produção de biomassa e inulinase por K. marxianus var. bulgaricus: influência das condições de cultivo. Tese (Doutorado em Ciências Biológicas). Instituto de Biociências, Universidade Estadual Paulista, Rio Claro, 2005.

DE PAULA, F. C. Imobilização da inulinase de Kluyveromyces Marxianus var. Bulgaricus Atcc 16045: caracterização e produção de açúcar Invertido em biorreator Unesp (Doctoral Dissertation, Universidade Estadual Paulista), 2007.

DILIPKUMAR, M.; RAJASIMMAN, M.; RAJAMOHAN, N. Optimization of inulinase production from garlic by Streptomyces sp, in solid state fermentation using statistical designs. Biotechnol. Res. Int., v, 2011, p 7, 2011.

GAO LM; CHI ZM; SHENG J; WANG L; Li J; GONG F. Inulinase-producing marine yeasts: evaluation of their diversity and inulin hydrolysis by their crude enzymes. Microbiol. Ecol., 54:722729, 2007.

GONG, F., SHENG, J., CHI, Z., LI, J. Inulinase production by a marine yeast Pichia guilliermondii and inulin hydrolysis by the crude inulinase. J. ind. Microbial. Biotechnol., v. 34(3), p. 179-185, 2007.

HAEGLER, A.N.; MENDONÇA-HAEGLER, L.C. Yeast from marine and stuarine waters with different levels of pollution in the State of Rio de Janeiro, Brazil. Appl. Environ. Microbiol., v.41, n.1, pp.173-178, 1981.

HENSING, M., VROUWENVELDER, H., HELLINGA, C., BAARTMANS, R., VAN DIJKEN, H. Production of extracellular inulinase in high-cell-density fed-batch cultures of Kluyveromyces marxianus. Appl. Microbial. Biotechnol., v. 42(4), p. 516-521, 1994.

KAMEDA, E.; LANGONE, M.A.P.; COELHO, M.A.Z.; Removal of Polymeric Filter Cake in Petroleum Wells: a Study of Commercial Amylase Stability. J. Petrol. Sci. Eng., 59(3), 263-270, 2007.

KIRBY, D.K.; DAVIES, R. Thiol induced release of invertase from cell walls of Saccharomyces fragilis. Biochim. Biophys. Acta, Baltimore, v. 201, p. 261-266, 1970.

PESSONI, R., OLMEDO, P. M., CLEMENTE FILHA, A. C., \& FIGUEIREDO-RIBEIRO, R. C. Produção de concentrados de frutose por inulinases de Penicillium janczewskii e atividade sobre o nível de glicose plasmática em ratos diabéticos. Ciênc. Tecnol. Aliment., v. 24, p. 372-377, 2004.

PIMENTEL, T.C., GARCIA, S., PRUDENCIO, S. H. Aspectos funcionais, de saúde e tecnológicos de frutanos tipo inulina. Bol. Centro Pesqui. Process. Aliment., v. 30(1), 2012.

MILLER, G. L. Use of dinitrosalicylic acid reagente for determination of reducing sugar. Anal. Chem., v. 31, n. 3, p. 426-428, 1959.

NASCIMENTO, D. S., VALASQUES JUNIOR, G., FERNANDES, P., RIBEIRO, G. C., LIMA, D. M., GÓES-NETO, A., ASSIS, S. A. D. Production, characterization and application of inulinase from fungal endophyte CCMB 328. An. Acad. Bras. Cienc., v. 84(2), p.443-454, 2012.

NEAGU, C., \& BAHRIM, G. Inulinases - a versatile tool for biotechnology. Innovat. Rom. Food Biotechnol., v.9(1), p.1-11, 2011.

NICAUD, J-M., MADZAK, C., BROEK, P.V.D, GYSLER, C., DUBOC, P.,N IEDERBERGER, P. e GAILLARDIN, C. Protein expression and secretion in the yeast Yarrowia ipolytica". FEMS Yeast Res., v.2, n.3, p. 371-379; 2002. 
NUNES, P.M.B. Intracellular lipase production by Yarrowia lipolytica using diferente carbon sources. Chem. Eng., v.38, 2014.

PEREIRA-MEIRELLES, F.V., ROCHA-LEÃO, M.H. SANT'ANNA, G.L. A stable lipase from Candida lipolytica - cultivation conditions and crude enzyme characteristics. Appl. Biochem. Biotechnol., v.63-65, p.73-85, 1997.

PEREIRA-MEIRELLES, F.V., ROCHA-LEÃO, M.H. SANT'ANNA, G.L. Lipase location in Yarrowia lipolytica cells. Biotechnol. Lett., v.22, n.1, pp.71-75, 2000.

PÉREZ-CAMPOS, F. M. \& DOMINGUES, A Factors Affecting the Morphogenetic Switch in Yarrowia lipolytica. Cur. Microbiol., v. 43, p. 429-433, 2001.

PESSOA JUNIOR, A. Obtenção de inulinase: recuperação e ampliação de escala. Tese de Doutorado, Faculdade de Ciências Farmacêuticas, Universidade de São Paulo, São Paulo, 1995.

SOUZA-MOTTA, C. M. D., CAVAlCANTI, M. A. D. Q., PORTO, A. L. F., MOREIRA, K. A., \& LIMA FILHO, J. L. D. Aspergillus niveus Blochwitz 4128URM: New source for inulinase production. Bras. Arch. Biol. Technol., v. 48(3), 3. 43-350, 2005.

TRIVEDI, S.; DIVECHA, J.; SHAH, A. Optimization of inulinase production by a newly isolated Aspergillums tubingensis CR16 using low cost substrates. Carb. Polyme., v, 90, p, 483- 490, 2012.

TSUGAWA, R., NAKASE, T., KOYABASHI, T., YAMASHITA, K. e OKUMURA, S. Fermentation of n-paraffins by yeast. Part III.- Ketoglutarate productivity of various yeasts". Agr. Biol. Chem., v.33, p.929-938, 1969.

ZINJARDE S. S., PANT A.: Emulsifier from a tropical marine yeast Yarrowia lipolytica NCIM3589. J. Basic. Microbiol., 42, 67-73, 2002. 